\title{
Research on the Legal System of Government and Social Capital Cooperation (PPP) Model
}

\author{
Jiamian Yu \\ Law School of Southwestern University of Finance and Economics, Chengdu, Sichuan, 611130
}

Keywords: government and social capital cooperation, institutional evolution, PPP law, supply-side reform

\begin{abstract}
In recent years, the rapid development of the PPP model has made a great leap, and the corresponding theoretical studies and the rule of law system have not achieved corresponding synergies. This paper attempts to clarify and redefine the definition of PPP at home and abroad, combing the process of China's PPP rule of law from the perspective of legal system evolution, and analyzing the existing problems. By analyzing the transplanting and borrowing of the legal system and combining with the local rule of law system, this paper puts forward the corresponding theoretical suggestions for the optimization of PPP rule of law in China so that it can better serve the "supply-side reform" under the new normal of new economy in China.
\end{abstract}

\section{Introduction}

In recent years, PPP has become a popular policy tool both internationally and domestically to provide social public services and to promote social and economic development. In the meantime, PPP has also been considered in the general sense as more than one between government and social capital Kind of institutional arrangements for long-term cooperation. However, it is difficult for academics and practitioners to reach consensus on the connotation and extension of PPP. There are various translation methods for PPP, such as public-private partnership, public-private partnership, partnership between public and private institutions, private open public service, public-private cooperation System and so on. In fact, there is not a precise definition and explanation accepted by theorists and practitioners at home and abroad so far. Its related practices and theories are also evolving. To sum up, the reasons for the current situation are as follows: Firstly, the extension of PPP itself is very extensive and not fixed. From the purely managed OM to the BOT and the BTO involved in the construction and operation of the system, the PPP is involved. Secondly, the definition of PPP by different disciplines and Commentary focuses on different points. Third, the different attitudes of the history of countries to different PPPs and the different legal rules and regulations have also resulted in the regional differences and legal differences in understanding PPP.

What is PPP? That is, the abbreviation of "Public-Private Partnerships" in English, which has been translated into PPP or "public-private partnership" or "public-private partnership" earlier by our theoretical and practical circles. Our country's Taiwan region is generally translated as "public-private partnership." After 2014, the official documents of China's National Development and Reform Commission and the Ministry of Finance all called "the mode of cooperation between government and social capital."

\section{The institutional evolution of PPP legal system in our country}

In the 1980s, there have been some PPP projects in infrastructure and public utilities in our country. As a new management model, the stage of reforming history is inextricably linked with the accelerating pace of urbanization, marketization and internationalization in our country. The first phase of PPP development in China started in the BOT period of foreign investment in the early 1990s and peaked around 1998 with an average annual number of 60-70 projects. After 1998, due to the impact of the Asian financial crisis, the PPP project gradually dropped back to 30 projects a year or so before and after 2000. The second phase began in 2001 with Chinese private capital as the 
main force of participation, which started to fall in 2008 and was hit by the combined effect of the U.S. financial crisis and the domestic 4 trillion yuan policy in 2009, all the way down to the bottom of 2012 and hovering until 2014. It is particularly noteworthy that after the two financial crises of 1998 and 2008, the large-scale reversal of PPP development in China occurred from large-scale institutional reversal from PPP to PUP the change.

The third stage of institutional change is from the beginning of 2012, with the prominent local debt crisis of local governments and the surge of debts of state-owned enterprises, the central government started to reintroduce the development of PPP mode through dual policy paths of "Forced" and "Guided" New ideas. On the one hand, through the corresponding laws and regulations and other system design, squeeze the financing space of local government financing, reflecting the Forced effect. In 2012, the Ministry of Finance, the National Development and Reform Commission, the People's Bank of China and the China Securities Regulatory Commission jointly issued the Circular on Suppressing the Financing of Illegal Activities by Local Governments (Caikuai [2012] No. 463), which clarified the requirement of "16 not to be honored". In September 2014, the State Council promulgated the "Opinions of the State Council on Strengthening Management of Local Government Debts" (Guo Fa [2014] No. 43), which requires local government financing platforms to divest government financing functions and not add new government debts. On the other hand, the central government has promulgated various laws and policies guiding and encouraging PPP in a timely manner. The "Decision of the CPC Central Committee and the Central Government on Several Major Issues for Deepening Reform" adopted by the Third Plenary Session of the 18th Central Committee of the CPC in 2013 clearly defined the idea of "actively developing a mixed ownership economy" and proposed here that "allowing social capital to enter the public service infrastructure and operation ". In 2014, the State Council successively issued No. 37 Document and No. 43 Document. In November 2014, the State Council promulgated the Guiding Opinion of the State Council on Encouraging Social Investment in the Key Areas of Innovation and Development (Guo Fa [2014] No. 60), reiterating the "Promotion of PPP Model" and "Seriously Summarize experience and strengthen policy guidance, and actively promote the PPP model in the areas of public services, environmental resources, ecological protection and infrastructure, standardize the selection of project partners, introduce social capital and enhance the supply of public goods. "After that, the Ministry of Finance and the NDRC Double forward. From the end of 2014 to the first half of 2015, the "NDRC Guiding Opinion on the Cooperation of Government and Social Capital" (Document No. 2724 of Development and Reform Commission) was promulgated successively, and the "Questions of Ministry of Finance on Promoting the Use of Cooperation Pattern between Government and Social Capital (Cai Jin Document No. 76) and the Administrative Measures for the Purchase of Services by the Government (Provisional) (Cai Jin No. 113) and other relevant regulations and texts. At the local level, in the second half of 2015, almost all the provinces and municipalities rapidly adopted local policies and regulations based on the aforementioned central government documents. The PPP model was mentioned in several government reports. This heat has lasted until now, more and more widely.

\section{The current problems of PPP law in our country}

There are several stages in the development of PPP intermittently in our country. The evolution of the relevant legal system has been outlined above. Summary analysis is not difficult to find that there are still several prominent and temporarily unsolvable problems in China's PPP rule of law.

At present, our country has some deviations in the legislation of PPP. Statistics related system found that at least the legislative purpose of "divesting government debt", "increasing the supply of public goods," "complete the hybrid ownership", "innovation investment and financing mechanism", "defuse the risk of local government debt" and "public interest maximization" And many other expressions. When formulating the rules and regulations of their respective departments, all ministries are invariably inclined to incorporate the departmental goals of their own departments more or less into the legal documents. According to the view that "the policy is its own response", 
the uncertainty and decentralization of the purpose of the PPP rule will severely weaken the legitimacy foundation of PPP and affect the practical operability of PPP.

The PPP rule of law in our country is a foreign product, which is bound to be transplanted and borrowed from the system. This is also the requirement of the development of the rule of law. In the process of legal transplantation, there will be a "transplant effect" in the legal system, that is, the result and reaction of the transplantation of the legal system and the local original legal system for system convergence and factor fusion. One obvious aspect of the "transplant effect" is exclusivity. At present, there is incompatibility between PPP legal transplantation in our country and the existing legal system and ideology in our country. For example, there is a serious conflict between the competitive negotiation policy required by the current PPP and the traditional "Bidding and Tendering Law" in our country. There is a serious incompatibility between the PPP project land use and the current land control laws and regulations. How to eliminate the exclusion of PPP legal transplant and how to control the effect of legal transplantation have been restricted and influenced by local system elements and become the bottleneck that is urgently needed for the research of PPP legal transplantation.

\section{The optimization of PPP legal advice in China}

At present, there are various problems in the legal system of PPP in our country. In the final analysis, it is caused by the game of departmental interests and lacks the unified top-level design of the rule of law at a higher level. From the perspective of evolution of the legal system, the evolution of PPP's rule of law must take place in existing social networks based on the basic national conditions of our country (new era, new economy and new contradictions). Therefore, the evolution of PPP rule of law must be full of games. The status quo of the current departmental disputes and system chaos in PPP rule of law in our country is exactly the embodiment of "organizational game". In order to make the result of PPP rule-making in our country reach the balance of the system created by the game and to balance this system with the legislative goal and the rule of law, the author suggests the following measures should be taken to correct and optimize the network of PPP legal organization in our country.

With the rapid development of market economy, the government has gradually shifted from the central role of planning control system, which is completely rational government, to the limited rationality of service government. Before the traditional government, in the field of public goods and services, not only responsible for the supply of public goods and services, the monopoly control of public goods and services, but also to a very large extent the control and influence of other market players, that is, the government " Can not "," omnipresent ". However, in the process of rule of law in PPP, the government's authority to control public goods and services should be significantly weakened. The government should no longer be the authoritative center but the platform and channel for the exchange of various stakeholders in PPPs. Xing Huijiang pointed out that "the government under the PPP model should play the dual role of both a partner and a supervisor." In the opinion of the author, in the legislation of PPP law, the participation of non-governmental organizations and the public should be introduced, and the legal rule of law should be taken to ensure the legitimacy of public participation and guarantee the institutionalized response to the public's reasonable appeals. To summarize, the next step of our country's PPP rule of law needs to gradually evolve from government-led legislation into a collaborative legislation involving a multi-center, multi-agent participation system and to improve the system balance.

At present, there is a "dualization center" for the management of PPP mode in China. That is, the NDRC and the Ministry of Finance manage the approval of projects and the supervision of financial funds according to their respective powers. In other words, "the power of development and reform and fiscal control." Therefore, it is unrealistic to transplant and optimize the PPP legal system if we want to reinvent the wheel and surpass the existing political system and the established historical conditions. On the basis of fully drawing on and borrowing from abroad the advanced experience and legislative theory on PPP's rule of law and in combination with the actual conditions of our country's current national conditions and socio-economic development, we recognize the restraint 
of the existing legal system and streamline the State Council, ministries and commissions as well as local governments The Different Roles of the Government in the Legal System of. By adhering to the principle of "multiple appraisals and unification, uniform appraisals", it is a pragmatic and practical solution to formulate a unified and comprehensive PPP management system and correspondingly improve the design level of the PPP rule of law.

At present, the rule of law in PPP lags behind the complex situation of "treating floodwaters in Kowloon", resulting in chaos in the rule of law system. Fundamentally, the PPP law in our country spreads among different departments is a compound process of central government promotion and departmental policy learning and policy competition. This process inevitably leads to a clear multi-head management framework and logic. In fact, the game of cognition, logic, authority, responsibility, information and supervision of all the ministries and commissions under the "duality center" of the PPP rule of law has led to excessive unnecessary cost in the PPP rule of law. Therefore, the legislative purpose of unifying PPP rule of law should be clarified from the programmatic framework of the top-level design so as to avoid the logical conflict between fiscal control and the empowerment of development and reform. Secondly, it is necessary to streamline institutional arrangements such as powers, obligations and responsibilities among different departments, resolve conflicts of interests among various departments, strengthen trust mechanisms and cooperation and coordination mechanisms among various departments, and strengthen administration according to law and reasonable administration.

At present, China has hardly borrowed the relevant systems from abroad and set up corresponding PPP implementing agencies and promoting agencies in the process of rule of law in PPP. The sound development of the PPP model not only requires a sound guarantee of the rule of law, but also requires a reasonable and active executive body and promotion of operational implementation and communication and coordination. At present, except for the Ministry of Finance of the People's Bank of China under the CDM Fund Management Center, the Ministry of Finance has set up a temporary "PPP Center of the Ministry of Finance", there is no special PPP implementing agency, and no special agency for the promotion of PPPs across sectors and regions. Therefore, the author suggests that we should set up PPP implementing agencies and promoting agencies according to the needs of the development of PPP rule of law, establish PPP implementing agencies and promoting agencies, and ensure its relative independence, improve the role orientation, organizational setup, authority and responsibility, operating mechanism and hierarchy. Of course, the promotion agencies referred to in this article include dispute resolution agencies. This requires scholars and managers to conduct more in-depth research and lessons learned.

\section{Conclusions}

Since 2014, the development of the PPP Great Leap Development has drawn great attention from leaders, industry and theorists. PPP mode objectively requires a high degree of legalization, standardization and localization. How to Solve the Problem of Localization of Legal System in the Process of Rule of Law in PPP and How to Include It in the Background of "Supply-Side Reform", How to use this as an opportunity to promote the transformation of government functions involves both the transformation of concepts and concepts, It also involves the reform of the mechanism and system. By perfecting the corresponding rule of law system, we can provide the rule of law guarantee and results solidification for the new normalcy of PPP development in the era of "supply-side reform" and "new economy."

\section{References}

[1] David W. Gaffey: Outsourcing infrastructure: expanding the use of public-private partnerships in the United States [J]. "Public contract law journal", 2010, page353.

[2] Chen Xun, Li Dan: "PPP policy changes and policy learning model-1980-2015 PPP Central Policy Text Analysis", "China Administration", No. 2, 2017, 106 pages. 